\title{
Simulation of Gravity Feed Oil for Areoplane Fuel Transfer System
}

\author{
Y. G. Lv ${ }^{1, *}$, Z. X. Liu ${ }^{1}$, S. Q. Huang ${ }^{1}$, T. Xu ${ }^{2}$ \\ ${ }^{1}$ College of Power and Energy, Northwestern Polytechnical University, Xi'an 710072, China \\ ${ }^{2}$ Military Representatives office of NDMMP, Xi'an 710025, China \\ Email: lyg07391@163.com
}

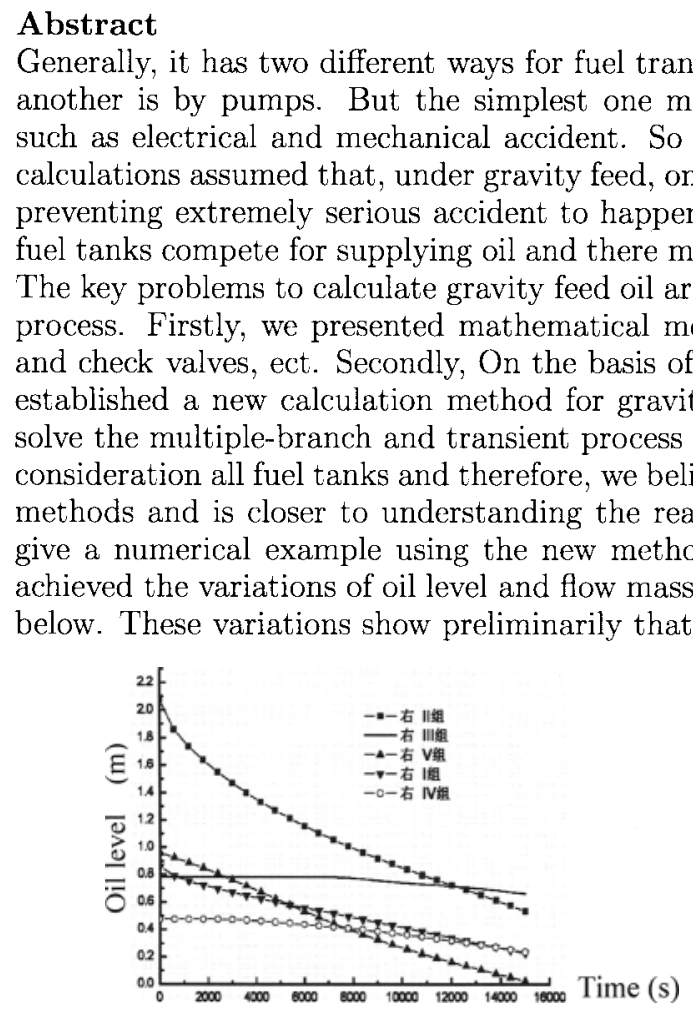

Figure 1: Variation of oil level in each fuel tank

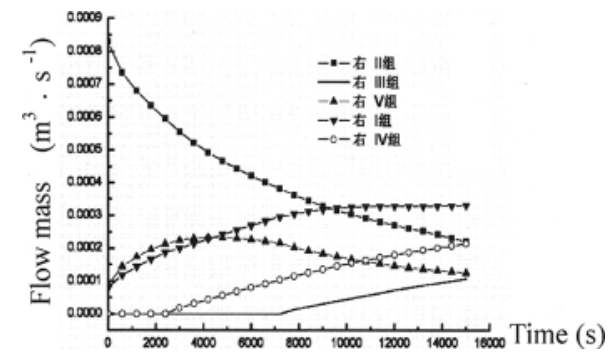

Figure 2: Variation of flow mass of each fuel tank

\section{REFERENCES}

1. Wu D Y. Network Algorithm of Internal Flow System. Journal of Aerospace Power, 1997; 17(6): 653-657

2. Chun S M. Network Analysis of An Engine Lubrication System. Tribology International, 2003; 36(8): $609-617$

3 Streeter V L, Wylie E B, Bedford K W. Fluid Mechanics. McGraw-Hill Companies, Inc. 1998 